\title{
Economic variables affecting punishment warmup
}

\author{
JEFFERY L. ARBUCKLE \\ University of Florida, Gainesville, Florida \\ and \\ KENNON A. LATTAL \\ West Virginia University, Morgantown, West Virginia
}

\begin{abstract}
Keypeck responding of a pigeon was maintained by a variable-interval (VI) 3-min schedule of positive reinforcement and punished according to a VI 30-sec schedule of electric shock presentations. During the short-session conditions, sessions lasted approximately $1 \mathrm{~h}$ and the subject was postfed immediately after the session. During the long-session condition, sessions lasted approximately $3 \mathrm{~h}$ and the subject was postfed approximately $12 \mathrm{~h}$ after the session. The short-session conditions consistently produced periods of low-rate responding, with a gradual increase in response rates at the beginning of the sessions. The long-session condition attenuated this warmup period. During the different conditions, the subject's behavior produced different proportions of the subject's total food intake. These results, therefore, may reflect the influence of economic context on response strength and the resulting effectiveness of a particular set of punishment parameters.
\end{abstract}

The context in which schedules of reinforcement operate affects the schedule-controlled performance of subjects (e.g., Herrnstein, 1970; Premack, 1965; Reynolds, 1961). One class of contextual variables has been described as economic (Hursh, 1980). Economic variables are those that affect the distribution and consumption of reinforcers or the distribution of stimuli used as reinforcers (usually food) throughout the entire day (both during and after any experimental sessions) of the subject. For example, "closed" and "open" economies refer to whether or not the number of reinforcers the subject receives depends entirely upon the subject's behavior. In closed economies, the subject's total food intake depends on the subject's behavior. In open economies, the subject's total food intake is provided by or is supplemented from sources not dependent upon the subject's behavior. These sources may be such events as postsession feeding or responseindependent food presentations. Hursh demonstrated that the openness of the economy affects such basic relations as that between response rate and reinforcement frequency. This relation has usually been described as direct, in that response rate increases as reinforcement frequency increases (e.g., see Catania \& Reynolds, 1968). Hursh asserted that this relation holds only in an open economy. If the economy is closed, there is an inverse relation in which response rate increases as reinforcement frequency decreases.

An economic analysis might also be extended to schedules of punishment. If a closed economy strengthens responding, in that response rates do not decrease as rein-

Requests for reprints may be addressed to Jeffery L. Arbuckle, Psychology Department, University of Florida, Gainesville, FL 32611. forcement frequency is decreased (as in a corresponding open economy), the same punishment parameters may not suppress the more strongly maintained responding in a closed economy as they would the responding in an open economy. Punishment schedules within the context of closed economies, therefore, may produce less response suppression than similar schedules in open economies. One punishment situation that may be likely to show economic effects is what Azrin and Holz (1966, pp. 398-399) described as a "vacation-from-punishment" effect, in which there is a higher degree of response suppression at the beginning of a punishment session than later in the session. This "warmup" period of the session appears to be a time of transition in which the opposing processes of reinforcement and punishment are reaching an equilibrium for the session. If warmups are periods of balancing of the two opposing processes, they may be sensitive to and likely to show effects of any additional controlling variables (such as economy) that may be added. Therefore, if economic variables affect punishment, it seems likely that such warmup effects may be sensitive to them. That is, punishment warmups obtained in an open economy may be attenuated by closing the economy because of the additional response strengthening.

In the present experiment, we examined the effect of economic variables on punishment warmup. After punishment warmup was obtained in the context of an open economy (the subject was postfed immediately), the economy was made more closed by increasing the session length (allowing more food to depend on the subject's behavior) and feeding any additional food approximately $12 \mathrm{~h}$ after the session (temporally separating the free, extrasessional food from the response-dependent food of the session). 
Table 1

Sequence of Conditions, Number of Sessions in Each Condition, Responses per Minute, Session Duration, Number of Reinforcers, and Amount Postfed

\begin{tabular}{lccccr}
\hline Condition & $\begin{array}{c}\text { Number of } \\
\text { Sessions }\end{array}$ & $\begin{array}{c}\text { Responses } \\
\text { per Minute }\end{array}$ & $\begin{array}{c}\text { Session Duration } \\
\text { (min) }\end{array}$ & $\begin{array}{c}\text { Number of } \\
\text { Reinforcers }\end{array}$ & $\begin{array}{c}\text { Amount } \\
\text { Postfed (g) }\end{array}$ \\
\hline Short Session (4-sec reinforcers) & 65 & 1.51 & 63.46 & 7.7 & 16 \\
Long Session (4-sec reinforcers) & 12 & 28.72 & 257.20 & 59.5 & 9 \\
Long Session (8-sec reinforcers) & 18 & 62.25 & 183.40 & 60.0 & 9 \\
Short Session (8-sec reinforcers) & 30 & 48.72 & 68.96 & 19.7 & 12 \\
\hline
\end{tabular}

Note-Responses per minute, session duration, number of reinforcers, and amount postfed are averages based on the last 10 sessions of each condition.

\section{METHOD}

\section{Subject}

A White Carneau pigeon was maintained at approximately $80 \%$ of its free-feeding weight. Its previous experimental history consisted of exposure to several different schedules of positive reinforcement. Water and grit were available continuously in its home cage

\section{Apparatus}

An operant conditioning chamber was used, which enclosed a space $28 \mathrm{~cm}$ long $\times 33 \mathrm{~cm}$ wide $\times 38 \mathrm{~cm}$ high. A $2.5-\mathrm{cm}$-diam response key was located in the center of the work panel, $25 \mathrm{~cm}$ from the floor of the chamber. It was transilluminated by a green, $7-\mathrm{W} 110-\mathrm{V}$ ac bulb throughout the sessions except during reinforcer presentations. A minimum force of approximately $0.16 \mathrm{~N}$ was required to operate the key. General illumination of the chamber during the sessions was provided by an orange, $7-\mathrm{W} 110-\mathrm{V}$ ac bulb at all times except during reinforcer presentations. Reinforcers consisted of either 4- or 8-sec access to mixed grain in a standard food magazine, the opening to which was on the work panel, $5 \mathrm{~cm}$ from the right wall and $10 \mathrm{~cm}$ from the floor. The opening was illuminated by a white, $7-\mathrm{W} 110-\mathrm{V}$ ac bulb when the magazine was operated. Punishers consisted of single 0.076-sec pulses of $60 \mathrm{~Hz}$ ac electric shock that were delivered through a $10 \mathrm{k} \Omega$ series resistor to electrodes implanted around the subject's pubis bones (Azrin, 1959). Every $10 \mathrm{~V}$ was equivalent to approximately $1 \mathrm{~mA}$. Supporting relay circuitry and recording equipment were located in an adjacent room.

\section{Procedure}

The pigeon received preliminary keypeck training on a series of variable-interval (VI) schedules of increasing duration over several sessions. The terminal VI 3-min schedule was arranged such that at the end of an interval averaging $3 \mathrm{~min}$, determined by a constant-probability distribution of 12 intervals (Fleshler \& Hoffman, 1962), the availability of food was held and the next response delivered the reinforcer. Once responding was stable, shocks were presented conjointly according to a VI 30-sec schedule with a 5-sec unsignaled delay from the response producing the shock to the shock. Responses during the delay interval did not reset the interval. In a conjoint schedule, two or more independent schedules are arranged simultaneously on the same operandum. Therefore, for this experiment, pecks on a single key produced both reinforcers and punishers on each of their respective schedules. If a single keypeck was scheduled to deliver both a reinforcer and a punisher, only the reinforcer was delivered. The VI 30-sec schedule consisted of 50 intervals that were also constructed from the constant-probability distribution of Fleshler and Hoffman. Shocks were presented initially at $10 \mathrm{~V}$ and were increased gradually to $65 \mathrm{~V}$ across several sessions.

Sessions were conducted daily and lasted approximately $1 \mathrm{~h}$ during the short-session conditions, and approximately $3 \mathrm{~h}$ during the longsession condition. The subject was postfed immediately after the sessions during the short-session conditions and was postfed approximately $12 \mathrm{~h}$ after the session during the long-session condition. Water was available to the subject during the experimental sessions starting during the long-session condition and continuing throughout the remainder of the experiment. The reinforcer duration was also increased during the longsession condition from 4 to $8 \mathrm{sec}$ and remained at that duration throughout the remainder of the experiment. The sequence of experimental conditions is shown in Table 1. Conditions were changed when response rates over the most recent six sessions appeared stable upon visual inspection and there was no monotonic trend in the rates.

Quantification of punishment warmup was accomplished by measuring the appropriate segments of the cumulative response records to the nearest $1 / 32$ of an inch. Of the 90 measurements calculated, interobserver agreement was examined for $18(20 \%)$. Of these 18 measurements, 11 were identical and the remaining 7 were different by no more than $1 / 32$ of an inch (approximately $9 \mathrm{sec}$ ).

\section{RESULTS}

As shown in Table 1, the increase in reinforcer duration had no effect on the amount of food needed to be postfed to the subject after the long sessions. This indicates that the change in reinforcer duration had no effect on the total food intake of the subject. This, in addition to the general downward trend in punishment warmups during long sessions with both 4- and 8-sec reinforcers,

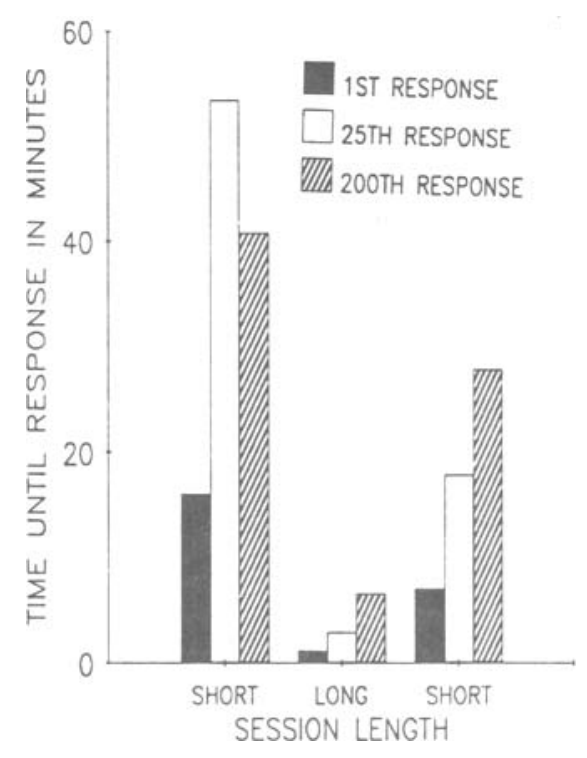

Figure 1. Average time (in min) until the 1st, 25th, and 200th response of each type of session. Averages were calculated across the last 10 sessions of each condition. All averages, therefore, were based on 10 observations, except the 25th and 200 th response of the first short condition. Due to the lack of 25 or 200 total responses in some cases, these averages were based upon five observations for the 25th response and one observation for the 200 th response. The short-condition sessions lasted approximately $1 \mathrm{~h}$ and the subject was postfed immediately. The long-condition sessions lasted approximately $3 \mathrm{~h}$ and the subject was postfed approximately $12 \mathrm{~h}$ later. 
led us to combine the data from both of the long-session conditions for analysis. Subsequently, all analyses involving the long-session condition were based on the data from the relatively stable long sessions with 8-sec reinforcers. All analyses are based on the last 10 sessions of each condition.

Figure 1 shows the average amount of time until the 1st, 25th, and 200th response of the session for the shortand long-session conditions. Due to the lack of 25 or 200 total responses in some sessions of the first short-session condition, these averages were based on five observations for the 25th response and one observation for the 200th response. This resulted in the anomalous-appearing longer average time for the 25th response than for the 200th response during the first short-session condition. The times for all three of the measured responses were longer during the short sessions than during the long sessions, however. These differences were large and consistent. The smallest difference was between the time to the 200th response from the long-session condition to the second short-session condition. This effect was over a fourfold
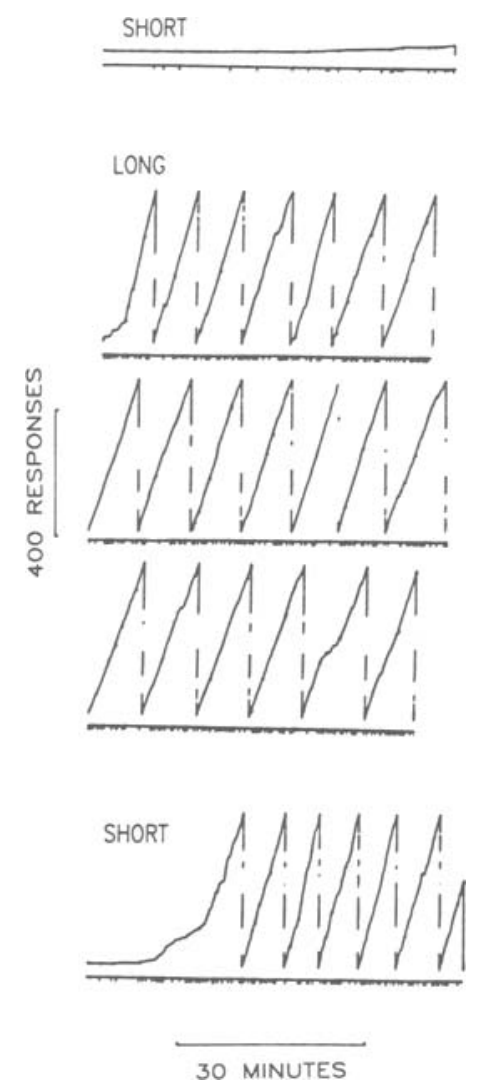

Figure 2. Representative cumulative response records for each condition. Short-session conditions are labeled "SHORT," and the longsession condition is labeled "LONG." Records are arranged from top to bottom in the order they occurred during the experiment. The long-session condition record is of a single session that has been broken into several segments. Deflections of the response pen indicate reinforcer deliveries, and deflections of the event pen indicate shock deliveries. difference between the conditions. The effects were also consistent in that they were reversible from the first to the second short-session condition. The short-session effects were recoverable, although they did not reach as high a level as they did in the first short-session condition.

Figure 2 shows representative cumulative response records from the three conditions. These records show the differences between the conditions in the session warmups. The record from the first short-session condition shows very low response rates (less than one response per minute) with no recovery over the entire duration of the session. The record from the long-session condition shows a brief period (approximately $4 \mathrm{~min}$ ) of variable response rates at the beginning of the session and relatively constant high rates throughout the remainder of the session. The record from the second short-session condition shows a period of relatively low and gradually increasing response rates during approximately the first 20 min of the session and relatively high constant rates throughout the remainder of the session.

Table 1 shows that the pigeon was postfed more during the short-session conditions than during the longsession condition. The subject was also postfed more during the first short-session condition than during the second short-session condition.

\section{DISCUSSION}

Punishment warmups, as shown by the cumulative response records (Figure 2) and time to the 1st, 25th, and 200th responses of the session (Figure 1), were longer during the short-session conditions than during the long-session condition. These differences were large and consistent. These warmup differences were due to session length, with the particular controlling variables possibly being differences in the number of reinforcers during the sessions, the amount of food postfed to the subject, when the subject was postfed, or a combination of these variables. All three of these particular session-length variables are economic in nature. The number of reinforcers delivered during the session and the amount of food postfed obviously affect session economy. As the number of reinforcers delivered increased and the amount of food postfed decreased, the economy became more closed. That is, more of the subject's total food intake became dependent upon the subject's own behavior. The economic impact of changing the postfeeding time is more speculative. When the postfeeding time occurred $12 \mathrm{~h}$ after the session, it may have become functionally part of another day and less potent in its effect on responding occurring in what was functionally another day. In fact, the subject was postfed the morning after the nightly experimental session. This temporal separation may have made the postfeeding less effective in opening the economy of the long sessions than the immediate postfeeding after the short sessions.

The effect of all of these aspects of session length on punishment warmup argues for a role for economic variables in the analysis of punishment. Closed economies may increase response strength and reduce the effectiveness of punishment at a constant set of punishment parameters. These results, therefore, extend the generality of economic processes and analyses from reinforcement to punishment.

\section{REFERENCES}

Azrin, N. H. (1959). A technique for delivering shock to pigeons. Journal of the Experimental Analysis of Behavior, 2, 161-163.

Azrin, N. H., \& Holz, W. C. (1966). Punishment. In W. K. Honig (Ed.), Operant behavior: Areas of research and application (pp. 380447). New York: Appleton-Century-Crofts.

Catania, A. C., Reynolds, G. S. (1968). A quantitative analysis 
of the responding maintained by interval schedules of reinforcement. Journal of the Experimental Analysis of Behavior, 11, 327-383.

Fleshler, M., \& Hoffman, H. S. (1962). A progression for generating variable-interval schedules. Journal of the Experimental Analysis of Behavior, 5, 529-530.

HerRnstein, R. J. (1970). On the law of effect. Journal of the Experimental Analysis of Behavior, 13, 243-266.

HURSH, S. R. (1980). Economic concepts for the analysis of behavior. Journal of the Experimental Analysis of Behavior, 34, 219-238.
Premack, D. (1965). Reinforcement theory. In D. Levine (Ed.), Nebraska symposium on motivation (pp. 123-180). Lincoln: University of Nebraska Press.

REYNOLDS, G. S. (1961). Behavioral contrast. Journal of the Experimental Analysis of Behavior, 4, 57-71.

(Manuscript received December 8, 1989.) 